\title{
Investigation of groundwater and soil quality near to a municipal waste disposal site in Silchar, Assam, India
}

\author{
M. Choudhury ${ }^{1}$ - D. S. Jyethi ${ }^{2}$ J. Dutta ${ }^{3,7}$ - S. P. Purkayastha ${ }^{4} \cdot$ D. Deb ${ }^{4} \cdot$ R. Das $^{4} \cdot$ G. Roy $^{1,4} \cdot$ T. Sen $^{5}$. \\ K. G. Bhattacharyya ${ }^{6}$
}

Received: 27 October 2020 / Accepted: 8 February 2021 / Published online: 4 March 2021

(c) Islamic Azad University (IAU) 2021

\begin{abstract}
Unscientific management of municipal solid waste is one of the direct sources of contamination in developing countries, such as India. The present investigation carried out during Oct-Dec 2019 attempts to assess the parameters, such as quality of groundwater and soil along three depths $(0-5,5-15$ and $15-30 \mathrm{~cm})$, in proximity to a dumping site in Silchar, a rapidly evolving city of North-East India. Standard protocols of soil and water quality assessments were carried out. The $\mathrm{pH}$ values of the surface soils were found to be slightly acidic. Decrease in acidity with increasing depth was observed in the study site. The relative abundance of the analyzed elements at all soil depths was $\mathrm{Zn}>\mathrm{Fe}>\mathrm{Ni}>\mathrm{Cu}>\mathrm{Cr}$. Weak correlation between the concentration of $\mathrm{Cu}, \mathrm{Fe}$ and $\mathrm{Zn}$, and the bulk density of the soil highlighted the micronutrient status of the soil. The impact of the nearby dumpsite on trace element contamination is indicated by the 'extremely contaminated' status of the soils with respect to geo-accumulation index. Majority of the groundwater samples exhibited $\mathrm{pH}$ levels below the desired limits, making it unfit for consumption by local communities. While $\mathrm{Fe}, \mathrm{Cu}$ and $\mathrm{Ni}$ levels in groundwater samples exceeded the guideline values, $\mathrm{Cr}$ and $\mathrm{Zn}$ concentrations were found to be within limits except one sample. Principal Component Analysis of the observed data was carried out to ascertain the predominant sources of contamination. The observations indicate the negative impacts of nearby dumpsite on environmental parameters, such as groundwater and soil quality, as highlighted in this research.
\end{abstract}

Keywords Contamination $\cdot$ Groundwater $\cdot$ Soil $\cdot$ Micronutrients $\cdot$ Environmental management

J. Dutta

joystu.dutta@gmail.com

1 Voice of Environment, Guwahati 781034, Assam, India

2 Indian Statistical Institute, North East Centre, Tezpur 784028, Assam, India

3 Department of Environmental Sciences, Sant Gahira Guru Vishwavidyalaya, Sarguja, Ambikapur 497001, India

4 Department of Chemistry, Karimganj College, Karimganj 788710, Assam, India

5 Department of Biosciences and Bioengineering (BSBE), Indian Institute of Technology Guwahati, Guwahati, Assam, India

6 Department of Chemistry, Gauhati University, Guwahati 781014, Assam, India

7 Commission on Ecosystem Management (CEM), South Asia, IUCN, 110016 New Delhi, India

\section{Introduction}

Humongous rise in waste generation in correlation with rising trends in urbanization and population has been observed across the world since last few decades. Municipal solid waste (MSW) management has been increasingly challenging in emerging urban spaces of Indian subcontinent. Recent times have seen exponential population growth, high population density in urban areas, diverse culture, changing food habits, and lifestyles as well as astronomical rise in biomedical waste generation as a result of COVID-19 pandemic in India (Kumar and Agrawal 2020). Open dumping of MSW is a common disposal method employed in developing countries (Mor et al. 2006; Menikpura and Basnayake 2009). Waste generation dynamics has changed over the years in 'transformed cities' which has undergone rapid population growth and industrial development over the last decades resulting in direct and indirect impacts over environmental health 
(Kumar et al. 2017). MSW Management is a growing urban issue in India and it has seen manifold escalation in recent years (Joshi and Ahmed 2016). As per the central pollution control board (CPCB) of India, the per capita waste generation has increased at an exponential rate (0.26-0.85 kg/day) (CPCB India 2018). Approximately $80-90 \%$ of the municipal waste is disposed off in landfills without scientific management practices leading to open burning and air, water, soil pollution consequences (Ahluwalia and Patel 2018). MSW at landfill sites are a potential contributor of harmful greenhouse gases eventually leading to groundwater contamination with leachate formation (Ngwabie et al. 2019). Unscientific management of MSW calls for immediate attention as it is a major roadblock in the path towards sustainable development. A direct relationship has been identified between precipitation and the seasonal variation of leachate generation in landfills (Trankler et al. 2005) as the infiltration of rainwater through the columns of MSW generates leachate in open dump sites. Elements in the leachate from these waste dumps percolate into subsurface aquifers, thereby contaminating the groundwater. Leachate constituents can be categorized as dissolved organic matter, inorganic components, trace metals and xenobiotic organic compounds. Among the different pollutants present in leachate, organic substances, ammoniacal nitrogen and trace elements are of significant concern to the environment (Paul et al. 2019; Yusof et al. 2009). In India as well as abroad, research has been carried out to assess the extent of soil and groundwater pollution in and around the municipal waste dumping sites of the metropolitan cities and understand its negative impacts on human health (Muller 1969; Lindsay and Norvell 1978; Dzik 1989; Kiekens 1995; Oyedele et al. 2008; Niloufer and Swami 2013). The outcome of these research activities clearly demonstrates the presence of toxic trace elements, such as $\mathrm{As}, \mathrm{Cr}, \mathrm{Pb}, \mathrm{Cu}, \mathrm{Ni}, \mathrm{Zn}, \mathrm{Hg}$, etc., in the soil as well as the groundwater. Heavy metal contamination has already been a major problem in urban space as discussed by (Dutta et al. 2019). However, there is a lack of similar studies exploring the extent and severity of soil and groundwater pollution in the emerging cities located in the geographically salient North Eastern regions of India. Obtaining a deeper understanding of the same is the present focus of this study. It is crucial that we obtain a better understanding of the extent and severity of soil and groundwater pollution in the cities of North East India as large sections of the population are directly dependent on extracted untreated groundwater for consumption as well as other daily requirements (Choudhury 2014; Deb et al. 2012; Kamboj and Choudhury 2013). Exposure to toxic elements through consumption of contaminated groundwater has been linked to adverse physiological disorders and carcinogenic effects (Goswami and Sarma 2008; Osazee et al. 2013; Rai et al. 2011; Eneje and Lemoha 2012; Rajkumar et al. 2010).

The present work was taken up to assess the physicochemical parameters and concentration of various trace elements in the soil and groundwater samples around the municipal waste landfill site at Meherpur in Silchar, Assam, India during October-December, 2019. Leachates from the dumpsite have the potential to contaminate the groundwater resources of the surrounding area. Groundwater is the only source of drinking water of the residents of the adjacent areas. The study region is underrepresented in terms of studies pertaining to increasing pollution and issues related to sustainable development. The objective of the present work is to carry out a preliminary investigation of the contamination levels of groundwater and soil at three different depths collected from a location in the vicinity of a municipal waste dumping site.

\section{Materials and methods}

\section{Study area}

Silchar, the headquarters of the Cachar district of Assam, a state in the North-Eastern region of India lies between $24^{\circ} 49^{\prime} \mathrm{N}$ to $24.82^{\circ} \mathrm{N}$ latitude and $92^{\circ} 48^{\prime} \mathrm{E}$ to $92.8^{\circ} \mathrm{E}$ longitude with an area of $15.75 \mathrm{~km}^{2}$ and mean altitude of $35 \mathrm{~m}$ above mean sea level. It is the second largest town in Assam. Silchar is the headquarters of Cachar district in the state of Assam in India. It is $343 \mathrm{kms}$ (213 mi) south east of Guwahati. It is ascribed as "Island of Peace" from India's then Prime Minister Smt. Indira Gandhi. The city area is located on the alluvial flat plains of River Barak and is routinely inundated during the rainy season. Ghagra River forms another important freshwater resource in the Barak Valley. Swamps, streams and small hills are the other notable features of Silchar. The Barak Valley including Silchar city falls in Seismic Zone V. Silchar has a borderline tropical monsoon climate (Köppen Am) slightly too hot in the "winter" or "cool" season to qualify as a humid subtropical climate (Cwa). The region is bordered by prolific tea estates. According to the 2011 census report, the city has a total population of 228,985. Then annual population growth from 2001-2011 was found to be $2.21 \%$ per year. Geographical remoteness, as well as poor infrastructural facilities and communication networks have been one of the reasons behind the slow economic growth of Silchar. However, in recent years, the town has witnessed increase in commercial activities and is experiencing steady development. Cachar Paper Mill (CPM) and ONGC industrial unit forms some of the flagship industrial operations of the area. Silchar is the gateway to the nearby states of Mizoram and parts of Manipur. The amount of municipal waste generated in the 


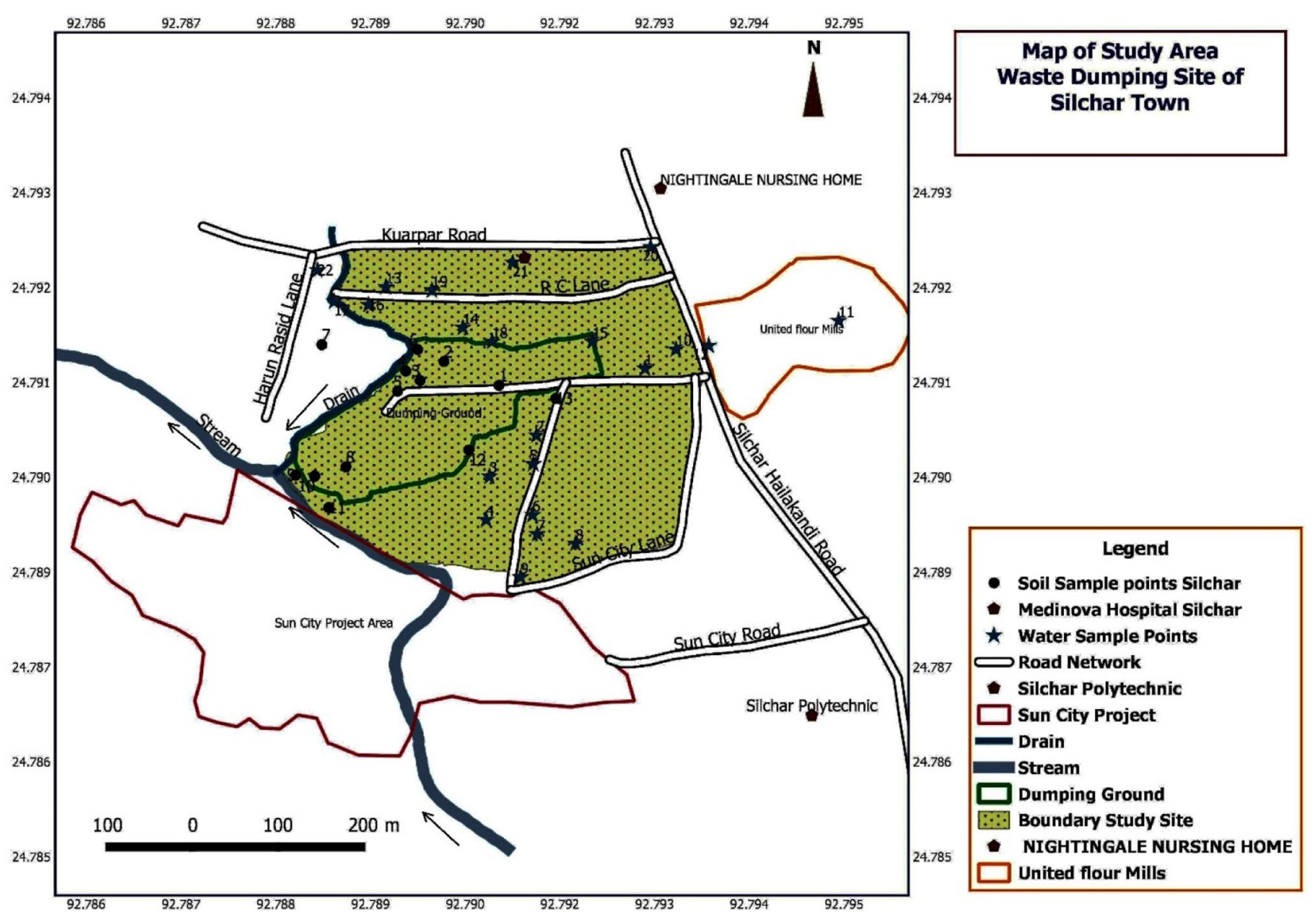

Fig. 1 Map of the study area indicating sample collection points

town is about 100 tons per day (CPCB 2011). The dumping area of Silchar municipality is located at Meherpur (Fig. 1) and the entire waste generation from the city and outskirts arrives in the dumping site, our current study area. The area of the dumping site is approximately $13,816 \mathrm{~m}^{2}$. It is in the low-lying riverine area of Nagapatty. Dumping in the area has been continuously done for the last 15-20 years. The total population in the immediate vicinity area is approximately 10,000 . The dumpsite contains a mixture of both organic and inorganic waste materials, such as food wastes, papers, cardboards, metals, tins, glass, leather, ceramics, battery waste, textile rags, plastics, etc.

\section{Sample collection}

The research was conceptualised and the preliminary sample collection was done as a part of student research project since December 2014. However, soil and groundwater samples were collected from the study site during the month of December 2019. For soil sample collection, thirteen sampling points in and around the dumping site were selected. Soil samples were collected from each site at the (a) surface
$(0-5 \mathrm{~cm}),(\mathrm{b})$ at a depth of $15 \mathrm{~cm}(15-20 \mathrm{~cm})$ and (c) $30 \mathrm{~cm}$ $(30-35 \mathrm{~cm})$ using a hand auger. A total of 39 soil samples were collected. Samples were allowed to dry in air for $48 \mathrm{~h}$ at room temperature. Samples were then disaggregated with mortar and pestle and sieved with a $2.36 \mathrm{~mm}$ sieve. The sieved samples were preserved in polyethene bags until further analysis. Groundwater samples were collected from 22 different points of the study site in pre-washed $\left(1: 1 \mathrm{HNO}_{3}\right)$ polyethene bottles. Distance between sampling points varied between 80 and $100 \mathrm{~m}$. The depth from which the groundwater samples were obtained varied between 24 and $36 \mathrm{~m}$ for the ring wells and hand pumps. Two liters of water were collected from each point and preserved in a refrigerator at $-4{ }^{\circ} \mathrm{C}$ until further analysis. Samples for trace element analysis were preserved with concentrated $\mathrm{HNO}_{3}$ acid (1 drop/10 ml) to avoid precipitation.

\section{Physicochemical characterization}

Physicochemical characteristics measured for the groundwater samples include $\mathrm{pH}, \mathrm{EC}$ (electrical conductivity), total suspended solids (TSS) and total dissolved solids 
(TDS). Soil samples were analyzed for $\mathrm{pH}$, electrical conductivity (EC), moisture content, porosity and bulk density. Standard analytical methods (APHA 2005) were used for the analyses. For the measurement of $\mathrm{pH}$ and $\mathrm{EC}$ of soil samples, $10 \mathrm{~g}$ of each sieved soil sample was suspended in $20 \mathrm{ml}$ of distilled water $(1: 2 \mathrm{w} / \mathrm{v})$ and shaken well in a mechanical shaker for $5 \mathrm{~h}$. The mixture was then allowed to settle to yield a supernatant liquid which was then filtered through Whatman No. 1 filter paper to obtain the soil extract. Water samples were used directly for the measurement of $\mathrm{pH}$ and EC. $\mathrm{pH}$ was measured by Labotronics LT-1 digital $\mathrm{pH}$ meter and EC by Systronics 304 conductivity meter. TDS was measured by weighing the dried solids remaining in each water sample after being filtered through a $1.2 \mu \mathrm{m}$ filter. TSS was calculated by weighing the filter paper before and after filtering $50 \mathrm{ml}$ of the water. The soil samples were dried in an oven at $105^{\circ} \mathrm{C}$ till dryness. The soil moisture was subsequently determined by calculating the moisture percentage. Porosity was calculated by the water saturation method. Bulk density of the soil samples was estimated from the dry weight of the soil and soil volume measurements.

\section{Trace metal analysis}

Open digestion method was followed to prepare the soil extract for metal analysis. $0.5 \mathrm{~g}$ of each of the soil samples was digested with $12 \mathrm{ml}$ of Aqua Regia $\left(9 \mathrm{ml}\right.$ of $1 \mathrm{M} \mathrm{HNO}_{3}$ and $3 \mathrm{ml}$ of $1 \mathrm{M} \mathrm{HCl}$ was used to prepare Aqua Regia) at $110{ }^{\circ} \mathrm{C}$ for $3 \mathrm{~h}$ in a digestion chamber, followed by evaporation to dryness. To the hot residue, $2.5 \mathrm{ml}$ of concentrated hydrochloric acid and $2.5 \mathrm{ml}$ of hydrogen peroxide were added for further oxidation, followed by accurate dilution to $50 \mathrm{ml}$ with double distilled water. $50 \mathrm{ml}$ of each of the acid preserved water samples was mixed well with $5 \mathrm{ml} 1 \mathrm{M}$ $\mathrm{HNO}_{3}$ and poured into a beaker. A few glass beads were added and the mixture was slowly boiled and eventually evaporated on a hot plate up to a volume of $10 \mathrm{ml}$ to $20 \mathrm{ml}$. $\mathrm{HNO}_{3}$ was added dropwise until the completion of digestion to ensure that the beaker did not dry up. The beaker was then washed thrice with double distilled water. The sample was finally filtered into a $50 \mathrm{ml}$ flask and the volume was made up to the mark. Atomic Absorption Spectrometer (AAS) (Shimadzu AAS 6300) was used for the analysis.

\section{Geo-accumulation index $\left(I_{\text {geo }}\right)$}

Geo-accumulation index $\left(I_{\text {geo }}\right)$ was employed to quantitatively assess the metal pollution load in the soil samples of the study area. It is determined by the following equation as described by (Boszke et al. 2004)

$$
I_{\text {geo }}=\log _{2}\left(\frac{C_{n}}{1.5 B_{n}}\right)
$$

where $C_{n}$ is the measured concentration of trace metal $n$ in the sample soil; and $B_{n}$ is the geochemical background value of element $\mathrm{n}$ in the average shale (Turekian and Wedepohl 1961). The factor 1.5 is used to account for the possible variations in the background data caused by lithological variations. $I_{\text {geo }}$ basically is the ratio between the measured concentration of trace metal in the sample soil and its geochemical background value in the average shale. This is to estimate the degree of contamination with respect to the metal in sample in comparison to its background levels.

$I_{\text {geo }}$ is classified into seven grades which are given below:

- $I_{\text {geo }} \leq 0$ (grade 0 ): Uncontaminated soil

- $0<I_{\text {geo }} \leq 1$ (grade 1 ): Uncontaminated to moderately contaminated soil

- $1<I_{\text {geo }} \leq 2$ (grade 2$)$ : Moderately contaminated soil

- $2<I_{\text {geo }} \leq 3$ (grade 3 ): Moderately to strongly contaminated soil

- $3<I_{\text {geo }} \leq 4$ (grade 4): Strongly contaminated soil

- $4<I_{\text {geo }} \leq 5$ (grade 5): Strongly to extremely strongly contaminated soil

- $I_{\text {geo }}>5$ (grade 6): Extremely contaminated soil

\section{Quality control and quality assurance}

Analytical-grade reagents were used for the analysis. Blank samples were analyzed for each batch of the analysis to ensure proper baseline correction. High-purity deionized water obtained from the Milli-Q system (Millipore, USA) was used throughout the analysis. Proper measures were adopted at each step, from sampling, storage and analysis, to ensure reliable and reproducible results. The AAS was calibrated using sets of at least five standards covering the whole range of concentrations encountered in the literature. The calibration curves were linear in the concentration range with linear regression coefficients $\left(R^{2}\right)>0.99$ for linear least-squares fit of data. Relative standard deviations (RSDs) of replicate measurements were $<10 \%$ for all the metals. Recoveries of metals were found to be between $82 \%$ for $\mathrm{Fe}$ and $96 \%$ for $\mathrm{Cu}$.

\section{Principal component analysis (PCA)}

Principal component analysis (PCA) is a statistical procedure that converts a set of possibly correlated numerical variables into a set of linearly uncorrelated variables called principal components. It is used to identify patterns in data. It was used to identify patterns in data. PCA was performed with SPSS 20.0. 


\section{Results and discussion}

The extent of environmental contamination around the open landfill site can be measured by monitoring the soil and groundwater quality using a set of measurable parameters. This section deals with the results of analysis of physicochemical parameters and trace elements present in soil and groundwater samples.
Physicochemical properties of soil samples

Physicochemical properties of soil samples are presented in Table 1. It was found that the $\mathrm{pH}$ of the soil samples varies between 4.2 and 7.0 which indicate acidic to neutral nature of the soil. The acidic nature can be attributed to the contamination of the soil samples by the acidic leachate produced at the dumping site (Goswami and Choudhury 2013).
Table 1 Trace metal content in soil samples

\begin{tabular}{|c|c|c|c|c|c|c|}
\hline \multirow[t]{2}{*}{ Sample no } & \multirow[t]{2}{*}{ Depth $(\mathrm{cm})$} & \multicolumn{5}{|c|}{ Metal content $(\mathrm{mg} / \mathrm{kg})$} \\
\hline & & $\mathrm{Fe}$ & $\mathrm{Cu}$ & $\mathrm{Cr}$ & $\mathrm{Ni}$ & $\mathrm{Zn}$ \\
\hline \multirow[t]{3}{*}{$\mathrm{S} 1$} & 0 & 21.1 & 4.9 & 3.6 & 7.2 & 49.0 \\
\hline & 15 & 20.7 & 5.4 & 5.1 & 7.4 & 44.0 \\
\hline & 30 & 21.0 & 5.2 & 5.7 & 7.8 & 92.6 \\
\hline \multirow[t]{3}{*}{$\mathrm{S} 2$} & 0 & 24.1 & 15.7 & 6.8 & 14.9 & 107.4 \\
\hline & 15 & 19.9 & 15.4 & 6.7 & 16.2 & 101.4 \\
\hline & 30 & 23.9 & 15.1 & 6.4 & 16.3 & 96.4 \\
\hline \multirow[t]{3}{*}{ S3 } & 0 & 39.6 & 13.6 & 4.0 & 20.6 & 265.7 \\
\hline & 15 & 38.9 & 24.7 & 3.4 & 8.9 & 145.4 \\
\hline & 30 & 40.1 & 25.1 & 2.4 & 24.1 & 210.4 \\
\hline \multirow[t]{3}{*}{ S4 } & 0 & 39.1 & 20.6 & 5.8 & 14.8 & 160.1 \\
\hline & 15 & 39.1 & 21.1 & 5.8 & 15.1 & 159.3 \\
\hline & 30 & 39.2 & 19.9 & 8.7 & 14.0 & 26.4 \\
\hline \multirow[t]{3}{*}{ S5 } & 0 & 30.5 & 8.8 & 7.1 & 11.1 & 19.5 \\
\hline & 15 & 30.9 & 9.1 & 6.8 & 10.2 & 18.9 \\
\hline & 30 & 31.4 & 9.9 & 6.4 & 9.9 & 14.2 \\
\hline \multirow[t]{3}{*}{ S6 } & 0 & 30.5 & 10.7 & 5.7 & 10.4 & 72.7 \\
\hline & 15 & 29.5 & 11.1 & 6.0 & 11.0 & 66.4 \\
\hline & 30 & 30.1 & 10.6 & 7.1 & 10.8 & 50.1 \\
\hline \multirow[t]{3}{*}{ S7 } & 0 & 29.9 & 4.9 & 3.6 & 32.1 & 175.7 \\
\hline & 15 & 27.7 & 5.5 & 3.7 & 26.9 & 145.3 \\
\hline & 30 & 27.6 & 5.7 & 3.8 & 26.2 & 338.9 \\
\hline \multirow[t]{3}{*}{ S8 } & 0 & 23.9 & 9.4 & 4.9 & 19.4 & 246.6 \\
\hline & 15 & 20.1 & 10.1 & 5.1 & 24.9 & 241.6 \\
\hline & 30 & 25.6 & 11.1 & 5.9 & 26.2 & 261.3 \\
\hline \multirow[t]{3}{*}{ S9 } & 0 & 25.9 & 6.7 & 4.6 & 17.4 & 170.1 \\
\hline & 15 & 25.1 & 7.1 & 5.1 & 18.0 & 126.4 \\
\hline & 30 & 24.9 & 7.4 & 9.4 & 17.9 & 131.4 \\
\hline \multirow[t]{3}{*}{$\mathrm{S} 10$} & 0 & 22.6 & 8.6 & 5.6 & 21.1 & 146.4 \\
\hline & 15 & 22.2 & 5.8 & 6.4 & 26.1 & 141.3 \\
\hline & 30 & 25.6 & 8.6 & 7.0 & 33.1 & 146.4 \\
\hline \multirow[t]{3}{*}{ S11 } & 0 & 34.6 & 10.3 & 4.9 & 15.1 & 160.4 \\
\hline & 15 & 34.5 & 10.9 & 4.9 & 17.8 & 156.6 \\
\hline & 30 & 35.7 & 11.4 & 5.5 & 17.0 & 156.4 \\
\hline \multirow[t]{3}{*}{$\mathrm{S} 12$} & 0 & 44.1 & 8.6 & 3.1 & 14.9 & 146.4 \\
\hline & 15 & 43.6 & 8.8 & 3.3 & 15.6 & 111.1 \\
\hline & 30 & 40.6 & 8.4 & 3.0 & 15.9 & 114.6 \\
\hline \multirow[t]{3}{*}{$\mathrm{S} 13$} & 0 & 31.9 & 7.1 & 2.6 & 9.6 & 210.4 \\
\hline & 15 & 31.6 & 7.5 & 2.8 & 14.1 & 169.4 \\
\hline & 30 & 34.5 & 8.6 & 3.0 & 14.9 & 201.2 \\
\hline
\end{tabular}


Fig. 2 Physicochemical characteristics of the soil samples collected at three depths from the study area. Error bars denote the standard deviation $(n=13)$

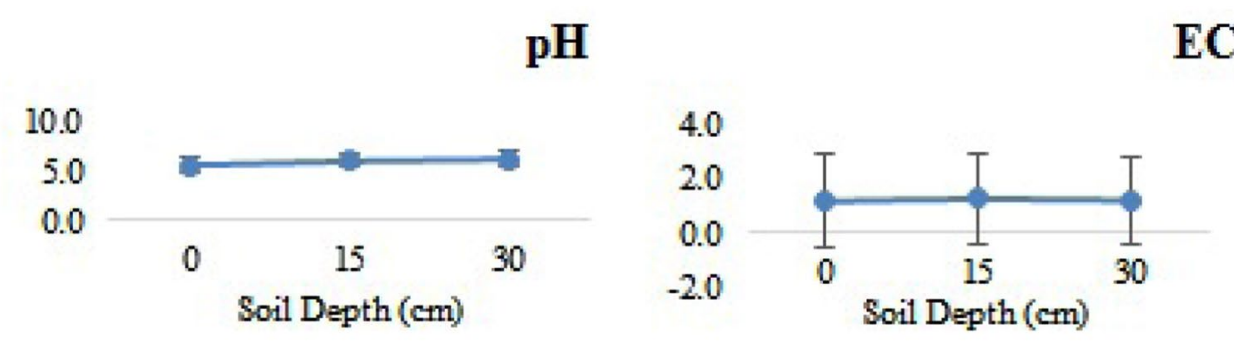

Moisture
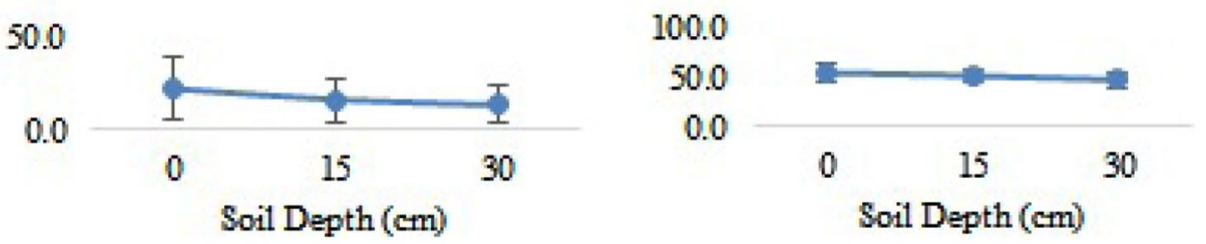

Bulk Density

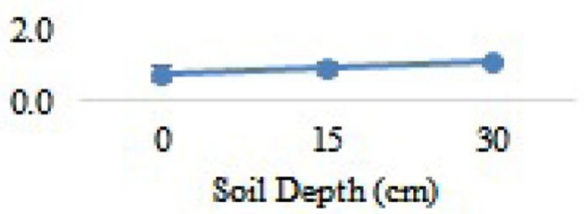

Mean $\mathrm{pH}$ of the surface soil across all sites was found to be $5.6 \pm 0.7$, while that of soil samples collected at depths of $15 \mathrm{~cm}$ and $30 \mathrm{~cm}$ was found to be $6.0 \pm 0.7$ and $6.2 \pm 0.7$, respectively. The results indicate a gradual decrease in the soil acidity with increasing depth in the soil profile of the study area (Fig. 2). EC is a measure of the ion exchange capacity. It is known to affect several parameters, such as soil texture, drainage, organic matter level, salinity, and even crop productivity. It can be observed that the EC values did not exhibit any trend with changing depth in the soil profile. The bulk density of soil is known to vary with changes in depth, porosity, organic matter content, etc. It also provides valuable insights regarding the occurrence of micronutrients in the soil essential for plant growth (Chaudhari et al. 2013). The present analytical data in Table 1 comply with the established direct correlation between bulk density and profile depth as well as an inverse correlation between bulk density and soil porosity (Anthony et al. 2012). The moisture content of a soil sample is dependent on its porosity. Moisture contents for all the soil samples collected from the different sites are presented in Table 1. It can be observed that the surface soils from all the sites have the highest water content and porosity.

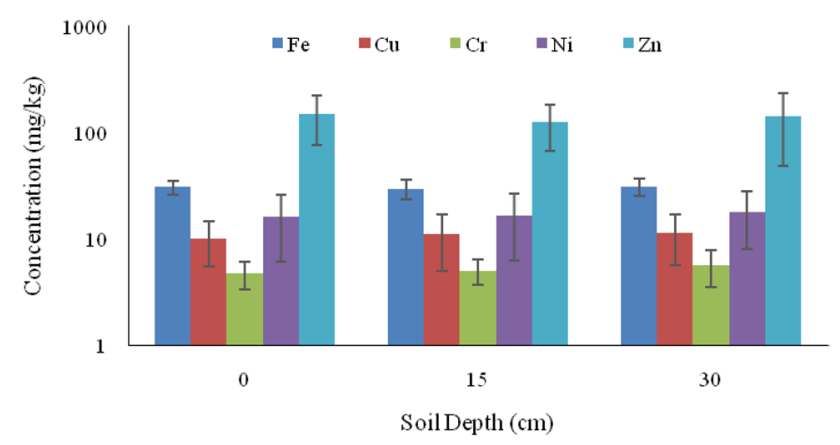

Fig. 3 Trace metal concentration in soil samples at three depths from the study area. Error bars denote standard deviation $(n=13)$

\section{Trace metal content in soil samples}

The individual concentrations of all the selected trace metals are given in Table 1. The mean concentration of the analyzed metals in soil samples across the study area did not exhibit any striking change concerning depth (Fig. 3). The following order in the abundance of the metals was observed at all three depths (surface, 15 and $30 \mathrm{~cm}$ ): $\mathrm{Zn}>\mathrm{Fe}>\mathrm{Ni}>\mathrm{Cu}>\mathrm{Cr}$. Azeez et al. (2011) reported trace metal levels in soil caused by MSW deposition in an emerging city in Abeokuta, 


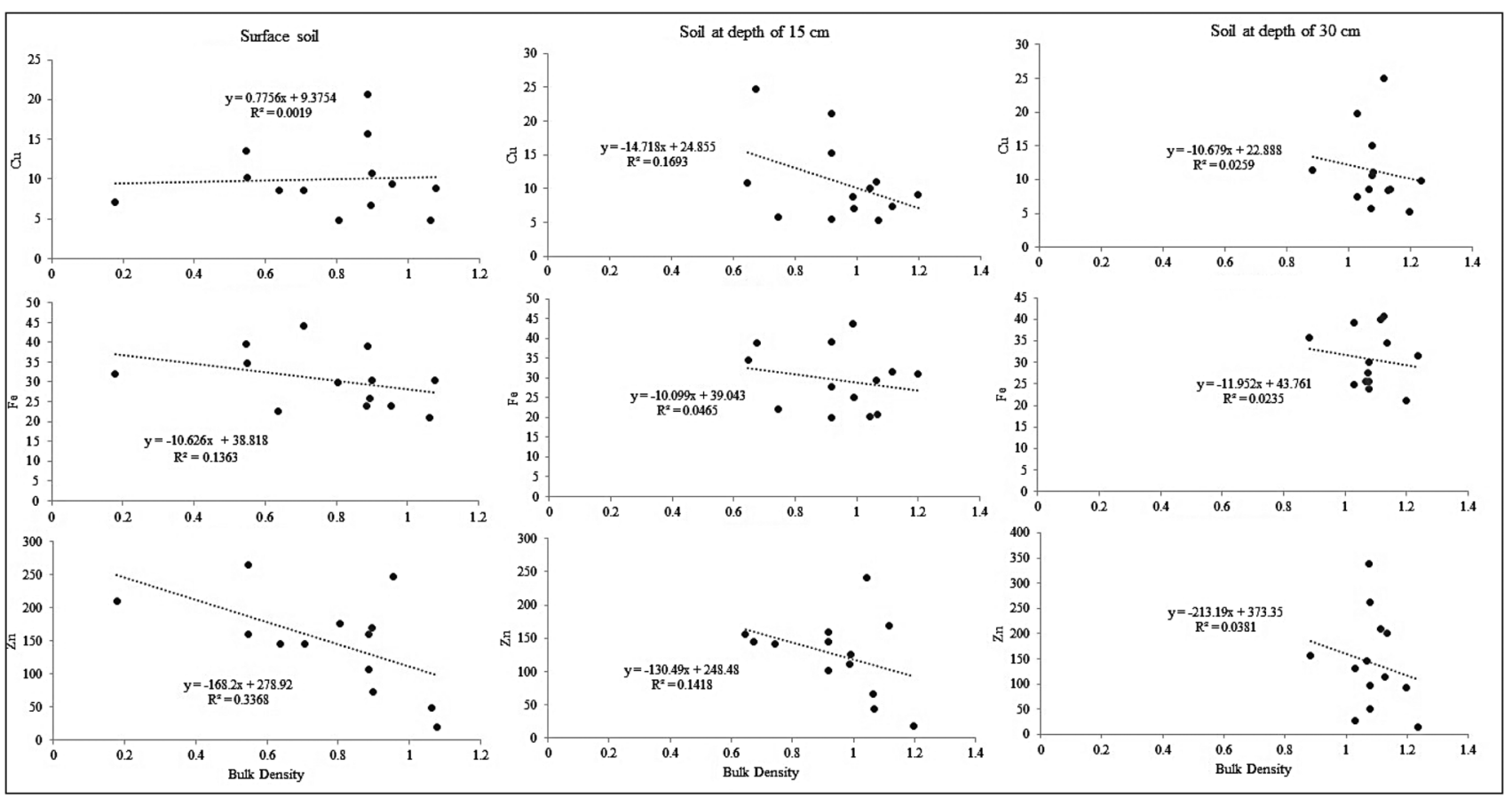

Fig. 4 Scatter plots of soil micronutrients $(\mathrm{Zn}, \mathrm{Fe}$, and $\mathrm{Cu})$ with bulk density at three depths

Table 2 Geo-accumulation index

\begin{tabular}{llllll}
\hline & $\mathrm{Cu}$ & $\mathrm{Ni}$ & $\mathrm{Fe}$ & $\mathrm{Cr}$ & $\mathrm{Zn}$ \\
\hline$C_{n}$ & 10.7 & 16.8 & 30.3 & 5.1 & 138.4 \\
$B_{n}$ & 45 & 68 & 47,200 & 90 & 95 \\
$I_{\text {geo }}$ & 9 & 10 & 20 & 12 & 14 \\
\hline
\end{tabular}

$C_{n}$ mean concentration of trace metal in the sample soil at three depths, $B_{n}$ geochemical background value in average shale of element (Turekian and Wedepohl, 1961), $I_{\text {geo }}$ geo-accumulation index

Nigeria. The highest concentrations of $\mathrm{Cu}, \mathrm{Cr}, \mathrm{Mn}$, and $\mathrm{Zn}$ were observed at a depth of $0-40 \mathrm{~cm}$ while $\mathrm{Pb}, \mathrm{Fe}$, and $\mathrm{Ni}$ accumulations were observed at depths below $40 \mathrm{~cm}$. The soil micronutrient status was examined from the concentration of $\mathrm{Cu}, \mathrm{Fe}$ and $\mathrm{Zn}$ present in the soil samples collected from a depth of $0-30 \mathrm{~cm}$ from the site. This investigation shows a weak correlation (Fig. 4) between the concentration of $\mathrm{Cu}, \mathrm{Fe}$ and $\mathrm{Zn}$, and the bulk density of the soil as also reported by (Laiho et al. 2004). High bulk density reduces water infiltration in turn resulting in increased surface runoff with pollutants.

The calculated $I_{\text {geo }}$ values are tabulated in Table 2. Results show that soil from the study area falls in the category of 'Extremely contaminated' with respect to the analyzed metals: $\mathrm{Cu}\left(I_{\mathrm{geo}}=9\right), \mathrm{Ni}\left(I_{\mathrm{geo}}=10\right), \mathrm{Fe}\left(I_{\mathrm{geo}}=20\right), \mathrm{Cr}\left(I_{\mathrm{geo}}=12\right)$ and $\mathrm{Zn}\left(I_{\mathrm{geo}}=14\right)$. Extremely high geo-accumulation indices indicate a long-term risk of environmental degradation and potential human exposure.

\section{Physicochemical properties of groundwater}

Physicochemical properties of groundwater samples are tabulated in Table S2. Mean $\mathrm{pH}$ of the samples was found to be $6.0 \pm 0.6$ with a range from 5.1 to 7.2. The standard limit of $\mathrm{pH}$ for drinking water is $6.5-8.5$. In the present study, it is found that the $\mathrm{pH}$ of $64 \%$ of the water samples was below 6.5, therefore rendering it as unfit for drinking purposes. Mean EC for the samples from the study area were found to be $0.2 \pm 0.1 \mathrm{mS} / \mathrm{cm}$. None of the samples exceeded the WHO guideline value of 1.4. TDS indicates the presence of total dissolved inorganic constituents in water. The TDS value of the water samples ranged between 80 and $590 \mathrm{mg} / \mathrm{L}$ which is within the WHO limit of $1000 \mathrm{mg} / \mathrm{L}$. However, the acceptable limit of TDS level in drinking water set by the Bureau of Indian Standards (BIS) is $500 \mathrm{mg} / \mathrm{L}$ which in the absence of an alternate source of water can be relaxed up to $2000 \mathrm{mg} / \mathrm{L}$. TSS is a measure of the mass of fine inorganic particles suspended in water. In the present investigation, the TSS value of the water samples is in between $33-339 \mathrm{mg} / \mathrm{L}$. The high concentration of suspended solids in water indicates that such water is aesthetically unacceptable for domestic uses (APHA 2002). The total hardness (TH) of water is a measure of the total concentration of calcium and magnesium ions present in the sample. The analytical results show that the range of TH was $17.8-30.6 \mathrm{mg} / \mathrm{L}$ which is far below the desirable limit of $300 \mathrm{mg} / \mathrm{L}$ in drinking water. 


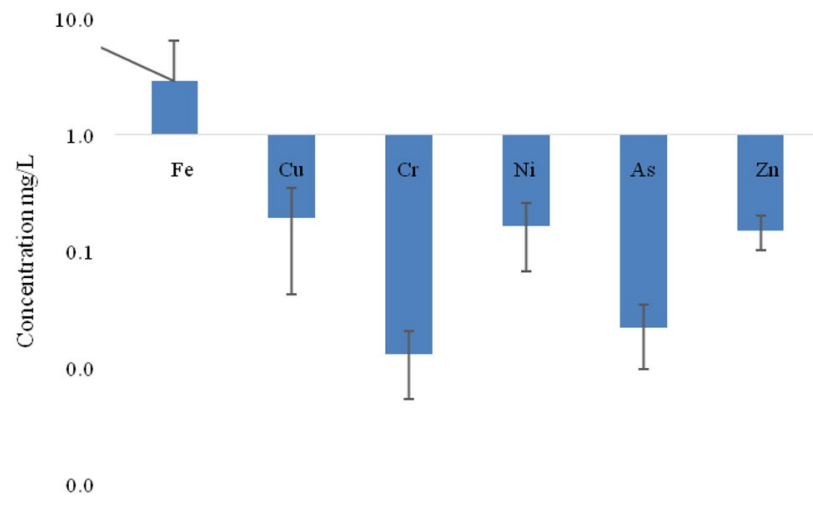

Fig. 5 Trace elements concentration in groundwater samples from the study area. Error bars denote standard deviation $(n=22)$

\section{Trace elements in groundwater}

Groundwater samples were analyzed for the trace elements $\mathrm{Fe}, \mathrm{Cu}, \mathrm{Cr}, \mathrm{Ni}$, As and Zn. (Fig. 5) represents the mean concentrations plotted on a logarithmic scale. Data for all the samples are tabulated in (Table 3).

The concentration of $\mathrm{Fe}$ varied in the range of $0.2-12.8 \mathrm{mg} / \mathrm{L}$ with a mean concentration of $2.9 \mathrm{mg} / \mathrm{L}$ which is above the permissible limit of $0.3 \mathrm{mg} / \mathrm{L}$, as declared by WHO (APHA 2002).

According to $\mathrm{WHO}$, the desirable limit of $\mathrm{Cu}$ in drinking water is $0.05 \mathrm{mg} / \mathrm{L}$ and its permissible limit is $1.5 \mathrm{mg} / \mathrm{L}$. Although the mean concentration of $\mathrm{Cu}$ in the analyzed water samples was $0.2 \mathrm{mg} / \mathrm{L}$ (which is within the permissible limit), it is far above the desirable value. The toxicological effects of Copper $(\mathrm{Cu})$ on human health and its mechanism of toxicity are well discussed in scientific literatures (Gaetke et al. 2014). Sources of $\mathrm{Cu}$ as reported by similar studies include leaching from open dumping sites of solid wastes (Kanmani and Gandhimathi 2013).

The mean concentration of $\mathrm{Cr}$ in the water samples was $0.01 \mathrm{mg} / \mathrm{L}$ which is below the permissible value of $0.05 \mathrm{mg} / \mathrm{L}$. Its concentration varied from 0.004 to $0.02 \mathrm{mg} / \mathrm{L}$ and most of the samples had $\mathrm{Cr}$ concentrations below detectable levels.

The permissible limit of $\mathrm{Ni}$ in the water samples is $0.03 \mathrm{mg} / \mathrm{L}$. The mean Ni level in the water samples was found to be $0.17 \mathrm{mg} / \mathrm{L}$ and the concentrations ranged between 0.02 and $0.4 \mathrm{mg} / \mathrm{L}$. Most of the samples demonstrated Ni levels far above the permissible limit which may cause detrimental effects on human health like respiratory, skin and cardiovascular diseases. Thus, all the samples are
Table 3 Concentration of trace elements in groundwater samples

\begin{tabular}{|c|c|c|c|c|c|c|}
\hline Sample no & $\mathrm{Fe}$ & $\mathrm{Cu}$ & $\mathrm{Cr}$ & $\mathrm{Ni}$ & As & $\mathrm{Zn}$ \\
\hline W1 & 3.9 & 0.1 & BDL & 0.1 & 0.03 & 0.1 \\
\hline W2 & 1.1 & 0.1 & BDL & 0.1 & 0.01 & 0.1 \\
\hline W3 & 0.3 & 0.02 & BDL & 0.1 & BDL & 0.2 \\
\hline W4 & 0.3 & 0.02 & BDL & 0.02 & 0.02 & 0.2 \\
\hline W5 & 0.9 & 0.1 & BDL & 0.1 & BDL & 0.1 \\
\hline W6 & 0.3 & 0.1 & BDL & 0.1 & 0.02 & 0.1 \\
\hline W7 & 0.9 & 0.2 & 0.004 & 0.2 & 0.1 & 0.2 \\
\hline W8 & 1.4 & 0.2 & BDL & 0.1 & 0.02 & 0.1 \\
\hline W9 & 10.6 & 0.6 & BDL & 0.1 & 0.03 & BDL \\
\hline W10 & 2.1 & 0.3 & BDL & 0.2 & 0.02 & 0.1 \\
\hline W11 & 0.2 & 0.1 & 0.01 & 0.1 & BDL & 0.2 \\
\hline W12 & 7.8 & BDL & BDL & 0.2 & 0.04 & 0.3 \\
\hline W13 & 0.5 & 0.1 & BDL & 0.3 & 0.01 & 0.2 \\
\hline W14 & 3.5 & 0.2 & BDL & 0.1 & 0.02 & 0.1 \\
\hline W15 & 1.8 & 0.1 & 0.02 & 0.1 & 0.02 & 0.2 \\
\hline W16 & 12.8 & 0.4 & 0.02 & 0.1 & 0.02 & 0.2 \\
\hline W17 & 2.2 & 0.2 & BDL & 0.3 & 0.01 & 0.2 \\
\hline W18 & 7.9 & 0.4 & 0.01 & 0.3 & 0.02 & 0.2 \\
\hline W19 & 1.9 & 0.2 & BDL & 0.3 & BDL & 0.1 \\
\hline W20 & 1.9 & 0.3 & BDL & 0.1 & BDL & 0.2 \\
\hline W21 & 0.4 & 0.3 & BDL & 0.4 & 0.01 & 0.1 \\
\hline W22 & 1.1 & 0.1 & 0.02 & 0.3 & 0.02 & 0.1 \\
\hline Mean & 2.9 & 0.2 & 0.01 & 0.2 & 0.02 & 0.2 \\
\hline Standard deviation & 3.5 & 0.1 & 0.01 & 0.1 & 0.01 & 0.05 \\
\hline
\end{tabular}

$B D L$ below detection limit 
unsuitable for drinking. Sridhar et al. (2017) reported values of Ni higher than permissible levels in south Chennai groundwater samples. Sewage water and leaching from corrosion of nickel alloy materials are considered one of the potential sources of Ni pollution.

The concentration of $\mathrm{Zn}$ in the water samples ranged from 0.06 to $0.28 \mathrm{mg} / \mathrm{L}$. The mean concentration was found to be $0.15 \mathrm{mg} / \mathrm{L}$ which is below the permissible limit of $5 \mathrm{mg} / \mathrm{L}$, as declared by WHO.

The mean As concentration in the water samples was found to be $0.02 \mathrm{mg} / \mathrm{L}$ which is within the permissible limit for drinking water in India of $0.05 \mathrm{mg} / \mathrm{L}$. Except the sample W7, all other samples collected from the study area have As concentration within the permissible limit, although the concentration of As in the groundwater sample of North Karimganj Block of neighboring district, Karimganj, has been reported to be far above the permissible limit for drinking water (Purkayastha et al. 2015).

\section{Principal component analysis}

Principal component analysis (PCA) is a multivariate analytical tool that is widely used in chemometrics. PCA was performed with SPSS 20.0. The output of PCA in the form of the component plot is shown in (Fig. 6). Seventy-eight per cent of the variance in the data was explained by the four components (PC1, PC2, PC3 and PC4) (Table 4).

$\mathrm{PC} 1$ explained $21 \%$ of the total variance and was loaded with $\mathrm{pH}, \mathrm{Ni}$ and $\mathrm{Zn}$. Ni and $\mathrm{Zn}$ are known to be sourced from discarded batteries. $\mathrm{Ni}$ is also known to arise from coal and gasoline emissions in urban areas. It has been reported that kitchen waste, ash, plastic and paper waste contribute to $82.3 \%$ of $\mathrm{Zn}$ contents in municipal solid waste in eight cities

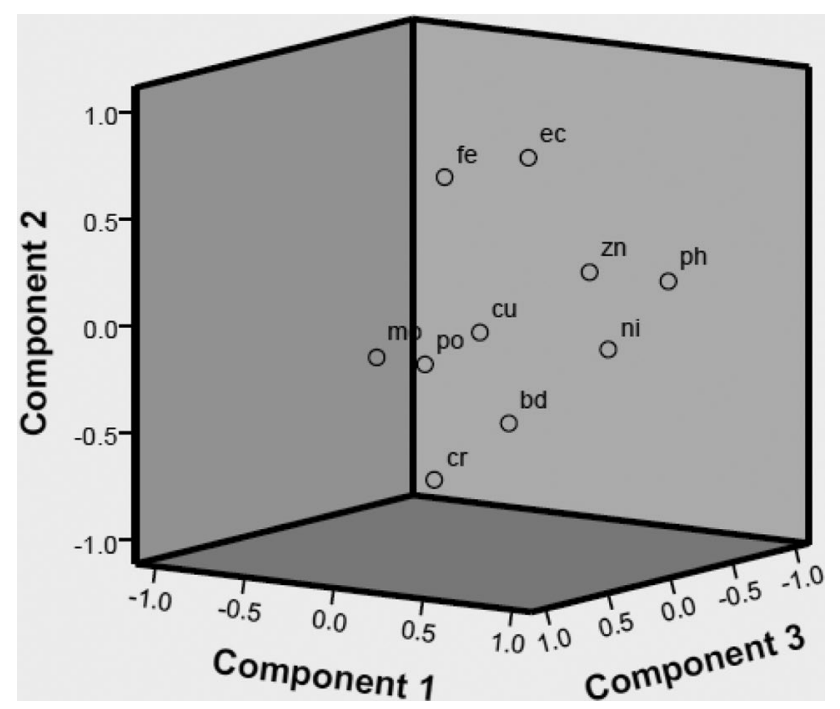

Fig. 6 Component plot in rotated space
Table 4 Rotated component matrix

\begin{tabular}{lcccc}
\hline & PC 1 & PC 2 & PC 3 & PC 4 \\
\hline $\mathrm{pH}$ & 0.7 & & & \\
Electrical conductivity (ec) & & 0.7 & & \\
Moisture (mo) & & & 0.8 & 0.5 \\
Porosity (po) & & & 0.7 & \\
Bulk density (bd) & & 0.6 & & 0.6 \\
$\mathrm{Fe}$ & & & & 0.9 \\
$\mathrm{Cu}$ & & -0.8 & & \\
$\mathrm{Cr}$ & 0.9 & & & \\
$\mathrm{Ni}$ & 0.8 & & & \\
$\mathrm{Zn}$ &
\end{tabular}

Extraction method: principal component analysis. Rotation method: varimax with Kaiser normalization, rotation converged in 7 iterations

in Eastern China. The authors also state that the aforementioned four categories have high universality in municipal solid waste (Long et al. 2011). The presence of $\mathrm{pH}$ in PC 1 indicates the physicochemical variability of $\mathrm{Ni}$ and $\mathrm{Zn}$.

PC2 explained $20 \%$ of the variance and was loaded with $\mathrm{EC}, \mathrm{Fe}$ and $\mathrm{Cr}$. Cr-containing waste includes sources, such as leather tanning, metal plating, colors, pigments and wood preservatives. Both $\mathrm{Cr}$ (III) and $\mathrm{Cr}$ (VI) are used for pigments in plastics, ceramics, and corrosion inhibition. Fe and $\mathrm{Cr}$ may have common sources, such as corrosion residues, metals, and steel products. It has been reported that Chromium was significantly bound to the organic matter and $\mathrm{Fe}$ and Mn oxides in Municipal Solid Waste Compost (MSWC) and Cow Dung Manure (CDM) (Bhattacharyya et al. 2005). Therefore, the association of $\mathrm{Cr}, \mathrm{Fe}$ and EC in PC2 can be explained by their association with organic matter, and the variability can be explained by electrical conductivity. PC3 explained $16 \%$ of the total variance and was loaded with moisture and porosity. These physicochemical properties are related. PC4 explained $16 \%$ of the total variance and was loaded with $\mathrm{Fe}$ and $\mathrm{Cu}$. $\mathrm{Cu}$ in municipal waste is sourced from kitchen waste, ash, plastic, and paper waste. $\mathrm{Cu}$, as well as Fe, is used in many consumer goods, such as electric appliances, private and public transport systems, as well as infrastructure systems for the supply and disposal of water, energy, and information (Kral et al. 2014). This can explain their similar pattern in the data.

\section{Conclusion}

Municipal Solid Waste Management is a burning issue in urban pockets of developing countries, such as India. The generation of hazardous chemical wastes as well as biomedical wastes from hospitals and industries leads to several healthcare emergencies (Joshi and Ahmed 2016; Mohan 
2019). In recent years, India has become the emerging recycling market; however, it lacks global standards (Bhattacharya et al. 2018). Lack of enforcement of appropriate centralized or de-centralised waste treatment system found missing (Singh 2020). In the current study, detailed analysis of the soil and groundwater samples for physicochemical parameters and trace elements showed that the quality of the soil and groundwater in and around the municipality dumping site at Nagapatty, Silchar has been affected by the open dumping of untreated MSW. The $\mathrm{pH}$ values of surface soils indicate a gradual decrease in acidity with increasing depth in the soil profile of the study area. The order of abundance of the elements at all depths (surface, 15 and $30 \mathrm{~cm}$ ) was found to be $\mathrm{Zn}>\mathrm{Fe}>\mathrm{Ni}>\mathrm{Cu}>\mathrm{Cr}$. A weak correlation between the concentration of $\mathrm{Cu}, \mathrm{Fe}$ and $\mathrm{Zn}$, and the bulk density of the soil highlighted the micronutrient status of the soil. Extremely high geo-accumulation indices indicate towards 'extremely contaminated' status of the soils with respect to all analyzed elements point towards the potential effect of the open dumping process. Majority of the groundwater samples exhibited $\mathrm{pH}$ levels below the desired limits. While $\mathrm{Fe}, \mathrm{Cu}$ and $\mathrm{Ni}$ levels in groundwater samples exceeded the guideline values, $\mathrm{Cr}$ and $\mathrm{Zn}$ concentrations were found to be within limits. The levels of As were also found to be within limits except for one sample. Open Municipal dumping sites possess negative impacts on environment and human health. Similar studies obtaining similar results elsewhere have proposed the closure of open dumping and landfill sites (Samadder et al. 2017). However, soil stratigraphy has a significant role to play in attenuation of leachate from landfill sites in contaminating the groundwater of the area (Aderemi et al. 2011). The findings obtained from this assessment have shown that groundwater of the study area is unreliable for drinking water supply purposes and the soil is unfit for agriculture and allied purposes, unless extensive remediation measures are taken in future. There is an urgent need to construct properly engineered sanitary landfill sites to curtail soil pollution and groundwater contamination. Municipal Solid Waste Management requires proactive attention with structured development plan to be laid out by the local governance of the area under consideration. Similar such practices are to be followed elsewhere and SOP (Standard Operating Procedure) for Municipal Solid Waste Management is to be developed. Timely monitoring and evaluation of waste management procedures is also required as a follow-up plan to make the procedures sustainable.

Supplementary Information The online version contains supplementary material available at https://doi.org/10.1007/s42108-021-00117-5.

Acknowledgements JD thanks TS for unconditional help in editing the manuscript. Sincere thanks are extended to the Head of the Department of Chemistry, Karimganj College and Gauhati University, Assam for their support during the study. JD also thanks the administration of Sant
Gahira Guru University, Sarguja for their encouragement in completion of this research work. Authors are also thankful to stakeholders of the study area for their cooperation during field study and sample collection especially local social worker, Prabal Dutta and members of the organization 'Voice of Environment' based in Assam, India.

\section{Compliance with ethical standards}

Conflict of interest The authors declare no conflict of interest in the current research work, whatsoever.

\section{References}

Ahluwalia, I. J., \& Patel, U. (2018). Solid waste management in India an assessment of resource recovery and environmental impact. Working paper no. 356. Indian Council for Research on International Economic Relations (Issue 356). https://icrier.org/pdf/ Working_Paper_356.pdf.

Anthony, A. O., John Adeyinka, A., \& Muraina, O. B. (2012). The inter-relationship of bulk density and porosity of some crystalline basement complex rocks: A case study of some rock types in Southwestern Nigeria. IOSR Journal of Engineering, 2(4), $555-562$.

APHA. (2002). Standard method for the examination of water and wastewater (17th ed.). Washington DC: American Public Health Association.

APHA. (2005). Standard methods for the examination of water and wastewater. Washington, DC: American Public Health Association.

Azeez, J. O., Hassan, O. A., \& Egunjobi, P. O. (2011). Soil contamination at dumpsites: Implication of soil heavy metals distribution in municipal solid waste disposal system: A case study of Abeokuta, Southwestern Nigeria. Soil and Sediment Contamination: An International Journal, 20, 370-386.

Bhattacharya, R. R. N. S., Chandrasekhar, K., Deepthi, M. V., Roy, P., $\&$ Khan, A. (2018). Challenges and opportunities: Plastic waste management in India. The Energy and Resources Institute, 24(2). https://www.teriin.org/sites/default/files/2018-06/plastic-waste -management_0.pdf.

Bhattacharyya, P., Chakraborty, A., Chakrabarti, K., Tripathy, S., \& Powell, M. A. (2005). Chromium uptake by rice and accumulation in soil amended with municipal solid waste compost. Chemosphere, 60(10), 1481-1486.

Boszke, L., Sobczynski, T., \& Kowalski, A. (2004). Distribution of mercury and other heavy metals in bottom sediments of the Middle Odra River (Germany/Poland). Polish Journal of Environmental Studies, 13, 495-502.

Chaudhari, P. R., Ahire, D. V., Ahire, V. D., Chkravarty, M., \& Maity, S. (2013). Soil bulk density as related to soil texture, organic matter content, and available total nutrients of Coimbatore soil. International Journal of Science and Research Publications, 3(2), 1-8.

Choudhury, M. (2014). Municipal solid waste generated by Silchar town and its impact on surrounding area of dumping site at Meharpur, Silchar, India. International Journal of Environment and Natural Sciences., 1, 41-43.

CPCB. (2011). Status report on municipal solid waste management. Central Pollution Control Board (CPCB). http://www.cpcb.nic.in/ divisionsofheadoffice/pcp/MSW_Report.pdf

CPCB India. (2018). MSW-generation and composition. https://cpcb. nic.in/uploads/MSW/Waste_generation_Composition.pdf

Deb, D., Purkayastha, S. P., \& Bhattacharya, K. G. (2012). Assessment of heavy metals and physico chemical parameters of water samples of the vicinity of the municipality dumping sites of 
Karimganj District, Assam, India. International Journal of Environmental Sciences, 2(3), 1408-1416.

Dutta, J., Zaman, S., \& Mitra, A. (2019). Are we taking poison every day? Indian Journal of Environmental Protection, 39(3), 283-289.

Dzik, A. Z. (1989). Cerebro vascular disease mortality rates and water hardness in North Dakota, South Dakota. Journal of Medicine, 42(4), 5-7.

Eneje, R. C., \& Lemoha, K. T. (2012). Heavy metal content and physicochemical properties of municipal solid waste dump soils in Owerri, Imo State. International Journal of Modern Engineering Research., 2(5), 3795-3799.

Gaetke, L. M., Chow-Johnson, H. S., \& Chow, C. K. (2014). Copper: Toxicological relevance and mechanisms. Archives of Toxicology, 88(11), 1929-1938. https://doi.org/10.1007/s00204-014-1355-y.

Goswami, D., \& Choudhury, B. N. (2013). Engineering and technology, chemical characteristics of leachate contaminated lateritic soil. International Journal of Innovative Research in Science, 2(4), 999-1005.

Goswami, U., \& Sarma, H. P. (2008). Study of the impact of municipal solid waste dumping on soil quality in Guwahati city. Pollution Research, 27(2), 327-330.

Joshi, R., \& Ahmed, S. (2016). Status and challenges of municipal solid waste management in India: A review, Rajkumar Joshi \& Sirajuddin Ahmed. Cogent Environmental Science, 2, 1139434.

Kamboj, N., \& Choudhury, M. (2013). Impact of solid waste disposal on groundwater quality near Gazipur dumping site, Delhi, India. Journal of Applied and Natural Science, 5(2), 306-312.

Kanmani, S., \& Gandhimathi, R. (2013). Investigation of physicochemical characteristics and heavy metal distribution profile in groundwater system around the open dump site. Applied Water Science, 3(2), 387-399.

Kiekens, L. (1995). Zinc. In B. J. Alloway (Ed.), Heavy metals in soils (2nd ed., pp. 284-305). Glasgow, UK: Blackie Academic and Professional.

Kral, U., Lin, C.-Y., Kellner, K., Ma, H.-W., \& Brunner, P. H. (2014). The copper balance of cities exploratory insights into a European and an Asian City. Journal of Industrial Ecology, 18(3), 432-444.

Kumar, A., \& Agrawal, A. (2020). Recent trends in solid waste management status, challenges, and potential for the future Indian cities-A review. Current Research in Environmental Sustainability, 2, 100011. https://doi.org/10.1016/j.crsust.2020.100011.

Kumar, S., Smith, S. R., Fowler, G., Velis, C., Kumar, S. J., Arya, S., et al. (2017). Challenges and opportunities associated with waste management in India. Royal Society Open Science, 4, 160764. https://doi.org/10.1098/rsos.160764.

Laiho, R., Penttilä, T., \& Laine, J. (2004). Variation in soil nutrient concentrations and bulk density within peatland forest sites. Silva Fennica, 38(1), 29-41.

Lindsay, W. L., \& Norvell, W. A. (1978). Development of DTPA soil test for $\mathrm{Zn}, \mathrm{Fe}, \mathrm{Mn}$ and Cu. Soil Science Society of America Journal, 42, 421-428.

Long, Y. Y., Shen, D. S., Wang, H. T., Lu, W. J., \& Zhao, Y. (2011). Heavy metal source analysis in municipal solid waste (MSW): case study on $\mathrm{Cu}$ and $\mathrm{Zn}$. Journal of Hazardous Materials, 186(23), 1082-1087

Menikpura, S. N. M., \& Basnayake, B. F. A. (2009). New applications of "Hess Law" and comparisons with models for determining calorific values of municipal solid wastes in the Sri Lankan context. Renew Energy, 34(6), 1587-1594. https://doi.org/10.1016/j. renene.2008.11.005

Mohan, V. (2019). 91\% premature deaths due to air pollution in low and middle-income countries: UNEP 1. The Economics Times. 10 May 2019. https://economictimes.indiatimes.com/news/environment/ pollution/91-premature-deaths-due-to-air-pollution-in-low-andmiddle-income-countries.unep/articleshow/69264417.cms

Mor, S., Ravindra, K., Dahiya, R. P., \& Chandra, A. (2006). Leachate characterization and assessment of groundwater pollution near municipal solid waste landfill site. Environmental Monitoring and Assessment, 118, 435-456. https://doi.org/10.1007/s1066 1-006-1505-7.

Muller, G. (1969). Index of geoaccumulation in sediments of the Rhine River. Geology Journal, 2, 108-118.

Ngwabie, N. M., Wirlen, Y. L., Yinda, G. S., \& VanderZaag, A. C. (2019). Quantifying greenhouse gas emissions from municipal solid waste dumpsites in Cameroon. Waste Management, 87(2019), 947-953.

Niloufer, S., \& Swami, A. V. V. S. (2013). Impact of municipal solid waste on the groundwater quality in Vijayawada City, Andhra Pradesh. Indian Journal of Applied Research, 3(4), 62-64.

Osazee, O. J., Obayagbona, O. N., \& Daniel, E. O. (2013). Microbiological and physicochemical analyses of top soils obtained from four municipal waste dumpsites in Benin City, Nigeria. International Journal of Microbiology and Mycology, 1(1), 23-30.

Oyedele, D. J., Gasu, M. B., \& Awotoye, O. O. (2008). Changes in the soil properties and plant uptake of heavy metals on selected municipal solid waste dump sites in IIe-Ife, Nigeria. African Journal of Environmental Science and Technology, 3(5), 107-115.

Paul, S., Choudhury, M., Deb, U., Pegu, R., Das, S., \& Bhattacharya, S. (2019). Assessing the ecological impacts of ageing on hazard potential of solid waste landfills: A green approach through vermitechnology. Journal of Cleaner Production, 236, 117643.

Purkayastha, S. P., Choudhury, M., Deb, D., \& Paul, C. (2015). Arsenic contamination in groundwater is a serious threat in the North Karimganj block of Karimganj district, Southern part of Assam, India. Journal of Chemical and Pharmaceutical Research, 7(8), 371-378.

Rai, S., Chopra, A. K., Pathak, C., Sharma, D. K., Sharma, R., \& Gupta, P. M. (2011). Comparative study of some physicochemical parameters of soil irrigated with sewage water and canal water of Dehradun City. India Archives of Applied Science Research, 3(2), 318-325.

Rajkumar, N., Subramani, T., \& Elango, L. (2010). Groundwater contamination due to municipal solid waste disposal-A GIS based study in Erode city. International Journal of Environmental Sciences, 1(1), 39-55.

Singh, S. (2020). Decentralized solid waste management in India: A perspective on technological options (pp. 290-304). New Delhi: National Institute of Urban Affairs.

Sridhar, S. G. D., Sakthivel, A. M., Sangunathan, U., Balasubramanian, M., Jenefer, S., Mohamed Rafik, M., \& Kanagaraj, G. (2017). Heavy metal concentration in groundwater from Besant Nagar to Sathankuppam, South Chennai, Tamil Nadu, India. Applied Water Science, 7, 4651-4662.

Trankler, J., Visvanathan, C., Kuruparan, P., \& Tubtimthai, O. (2005). Influence of tropical seasonal variations on landfill leachate characteristics-Results from lysimeter studies. Waste Management, 25(10), 1013-1020. https://doi.org/10.1016/j.wasma n.2005.05.004.

Turekian, K. K., \& Wedepohl, K. H. (1961). Distribution of the elements in some major units of the Earth's crust. Geological Society of America, Bulletin, 72, 175-192.

Yusof, N., Haraguchi, A., Hassan, M. A., Othman, M. R., Wakisaka, M., \& Shirai, Y. (2009). Measuring organic carbon, nutrients and heavy metals in rivers receiving leachate from controlled and uncontrolled municipal solid waste (MSW) landfills. Waste Management, 29, 2666-2680. 